\title{
Women and Stock Market Participation: Empirical Evidence from the Saudi Stock Market
}

\author{
Eman Ahmad Al-Amir ${ }^{1}$, Jaizah Othman ${ }^{2} \&$ Naila Iqbal Qureshi ${ }^{3}$ \\ ${ }^{1}$ King Saud University Medical City, Riyadh, Saudi Arabia \\ ${ }^{2}$ DCU Business School, Dublin City University, Dublin, Ireland \\ ${ }^{3}$ Faculty of Business and Administration, Princess Norah Bint Abdulrahman University, Riyadh, Saudi Arabia \\ Correspondence: Jaizah Othman, DCU Business School, Dublin City University, Glasnevin, Dublin 9, Ireland. \\ Tel: 60-13-245-4858. E-mail: jaizaho@yahoo.com
}

Received: March 2, 2020

Accepted: March 28, 2020

Online Published: April 30, 2020

doi:10.5539/ass.v16n5p29

URL: https://doi.org/10.5539/ass.v16n5p29

\begin{abstract}
The purpose of this paper is to explore the rareness of female Saudi traders in the Saudi stock market. This research employed the use of a cross-sectional study design with the data collection methods being mixed. The study makes use of a structured survey questionnaire and semi-structured interviews. The findings from the study clearly indicated that most of the respondents viewed education as an anchoring factor in breaking down social barriers as well as cultural barriers among the Saudi community. From the practical implications point of view, promoting women's participation in the stock market will help equality in job opportunities and contribute to wealth creation. Women constitute nearly half of the total population of the Kingdom of Saudi Arabia. The participation of these women in the Kingdom's economy is significant in terms of the enhancement and contribution to improving the socio-economic prospects of the state.
\end{abstract}

Keywords: participation, stock market, Saudi female, female trader, rareness

\section{Introduction}

\subsection{Background of Saudi Women}

The gender parity in Saudi Arabia is low as compared to other western countries. According to the World Economic Forum's 2016 Global, Gender Gap Report ranked Saudi Arabia at 141 out of 144 countries for gender parity, down from 134 out of 145 in 2015 (Hausmann, Tyson, \& Zahidi, 2015). This implies that women working and contributing to national income is lower as compared to men. For instance, in 2019, about $34.4 \%$ of the native workforce of Saudi Arabia were women, while the rest of the workers were men. In such male-dominated workforces, it is worthy to note that certain salient factors influence the equilibrium of women versus men workforce (Global Gender Gap Report, 2020). According to Human Rights Watch (2016), women have been vigorously campaigning for their rights and equality in the workplace. The women's status in Saudi Arabia has experienced a shift from traditional domesticity culture-bound and culture requirement to a new status where some can work and contribute as men. The current status of women in Saudi Arabia came to effect about 30 years or so, as a result of creation of an image of an "ideal woman," which was used later as a national symbol. Deo (2006) asserts that women are seen as "bearers of their cultural traditions," so that "defining women would allow a nation to define itself". Under Saudi law, all females must have a male guardian (wali), typically a father, brother, husband or uncle (mahram), but in 2019 this law was partially amended to exclude women over 21 years old from having a male guardian (Rajkhan, 2014). Such law places a typical Saudi woman in an inconvenient sphere where she can seek support independently alone without the approval of a male guardian. Sharia law does not forbid women from economic and political participation and permits them to work in certain sectors, but the workforce participation rate of Saudi women is among the lowest in the region as cultural teachings reinforce gender differences, granting men pre-eminence and authority over women (Al-Asfour, Tlaiss, Khan \& Rajasekar, 2017). Hence, such cultural teachings limit women and act as a general barrier to realization of women's freedom in the social-economic sphere.

\subsection{Saudi Women}

Half of the population of the Kingdom of Saudi Arabia is made up of women. As per the census carried out in 
2016, women constitute approximately $43.33 \%$ of the population, which is equivalent to 14.33 million of the total Saudi Arabian population, as per the Gulf Labor Markets and Migration website. Saudi Arabia, with its own conservative laws, has slowly started recognizing the importance of enabling some limited opportunities for women. The participation of these women in the Kingdom's economy is significant in terms of the enhancement and contribution to improving the socio-economic prospects of the state. While enduring socio-cultural and socioeconomic disparities have prevented Saudi women from participating in and profiting from trading in stock market trading (Almenberg \& Dreber, 2015), it is important to examine the various strategies for improving the situation of women in the stock market.

Female labor force participation has been one of the main sources of the Saudi labor market in developing the economy over the last fifty years (Asmari, 2008). It is conspicuous that there is a sluggish increase in the labor market in the number of females in comparison to the successive increase in the number of males. For instance, the rate of women's contributions reached approximately $7 \%$ in 2010 , while it was found to be around $3.5 \%$ in 2012; and that these situations are expected to continue until 2019 unless clear policies are adopted and a conducive climate for women's effective absorption and involvement made available.

A range of factors acts as an impediment to women's participation and investment in stock market trading. These include the psychological orientation of women, the stereotyping of women in the Arab world, and the weak economic status of women (Kaur \& Vohra, 2012). Previous studies have identified the apparent lack of confidence and optimism, disinterest in the stock trading issue, lack of perception concerning the relevance of stock trading, and stress as being among the key obstacles faced by women making stock market investment decisions.

The majority of these studies emphasize the idea that women have little interest in financial matters, and, thus, showcase limited interest in the stock market trading as they consider it to be an activity that is purely financial in nature (Kaur \& Vohra, 2012). Other studies have found that socio-cultural norms, values, traditions, and practices, especially those that allocate less value to the capabilities, aptitudes, and activities conventionally linked to women, as limiting constraints that restrict the movement of women in public life. Moreover, cumbersome processes, procedures, and formalities, along with faulty systems for retirement planning, have been highlighted as among the reasons for limited female involvement in stock market trading (Kaur \& Vohra, 2012; Vohra \& Kaur, 2018). Donohue (2011) identified a lack of wealth as being among the economic factors constraining women from investing in stocks. Empowerment, in this sense, maybe construed to mean proper government policies that support women in public service or public-private partnerships.

Moreover, as per the male guardianship policy, every Saudi woman obtains authorization from a male guardian, frequently the woman's husband, father, son, or brother, to access opportunities for education, travel, trading, work, gain business permits, and other restrictive practices (Kattan et al., 2016). These socio-cultural barriers may limit Saudi women wishing to participate in market trading because they must obtain permission from male guardians. Moreover, in the trading workplace, Saudi women face the prospect of complex rules, regulations, laws, and socio-cultural practices (Abalkhail, 2016).

This study sought to establish answers for the following specific research questions:

i. What are the factors concerning women's success in the stock trading market?

ii. What are the effective strategies for reducing the impact of the social barriers preventing Saudi women from participating in stock trading?

iii. What are the effective strategies for reducing the impact of the cultural barriers preventing Saudi women from participating in stock trading?

iv. What are the effective strategies for promoting the increased participation of Saudi women in stock trading?

The remainder of this paper is organized as follows: the second section discusses the literature review, followed by the research methodologies. The fourth section describes the findings of the analysis, and the last section covers the conclusion, including the policy implications derived from the research.

\section{Literature Review}

\subsection{The Education System and Women}

The development of the education system in Saudi Arabia has consistently grown together with the economy and vice versa. Previously, unlike their male counterparts, girls were restricted and stayed at home because of the traditional norms and gender segregation that did not allow them any say or equal opportunities in advancement 
(AlMunajjed, 2009). However, today, the investment in female education has become important for the development and further advancement of the economy. The education of women is related to various measures of development, such as reducing the population growth, and improvements in the health and nutrition, and literacy rate (AlMunajjed, 2009).

\subsection{Participation of Women in the Stock Market}

The participation of women in finance and business has witnessed a rapid increase in the past few decades (Kaur \& Vohra, 2012). Generally, nowadays, women not only work as corporate directors and officers, but they are also investors in companies (Hill et al., 2015). As women become major players in the global trading sector, it may be discomforting to acknowledge that female traders continue to face particularly discrete disadvantages as new, restricted participants in the stock exchanges and markets for security trading; detriments that are primarily linked to gender-based or sex-dependent differences (Almenberg \& Dreber, 2015). Furthermore, the limited access to opportunities for trading and insufficient investment information are factors that preclude women from investing in the market for stocks (Kaur \& Vohra, 2012). Considering these challenges, it is imperative to identify effective strategies to overcome these social and cultural barriers.

\subsection{Reviewing the Factors for Limited Stock Market Participation}

A study by Bernasek and Bajtelsmit (1996) in the U.S. State of Colorado using data generated from the U.S. Bureau of Census found that gender discrimination within the labor markets was a major factor contributing to the challenges faced while trading in the stock market. The author also revealed limiting factors that included discrepancies and inequality.

In a related study, Embrey and Fox (1997), who conducted a study among 839 single-person households in the U.S. State of Ohio using multivariate methods of analysis and the Tobit estimation technique as likelihood ratio tests, found a substantial difference in wealth as well as the expectations regarding inherence between women and men. These differences were linked to women's limited investment in risky assets, and, therefore, led to low participation (Fisher \& Yao, 2017). Moreover, Barber and Odean (2001) conducted a New York-based study covering 35,000 households to examine the impediments faced by women participating in stock market trading activities. Their study suggested that in considering the financial literacy requirements, it was the insufficiency or the absence of confidence that contributed to women's limited stock market trading participation.

Barber and Odean (2001) conducted another study on the rare involvement of women in stock trading and found a strong positive correlation between the participation of women in financial decision-making and their individual shares in the overall income of the household. Thus, a limited percentage of women, including Saudi women, have a lesser share in the total household incomes, which contributes to their low engagement in the financial decision-making processes, including those concerning their potential involvement in stock market trading (Kannadhasan et al., 2016).

Dyer et al. (2002) conducted a study among mutual fund traders. They found that, as a result of the lack of education and wealth, women were likely to take fewer risks compared to their male counterparts when making mutual fund investment decisions. The study conducted by Fusiller and Mueller (2004) among a population of stock investors, using multiple regression analyses as well as bivariate correlations, established that, as a result of the lower levels of educational achievement, women were likely to develop less trusting relationships with their brokers, as well as in their personal trading or investment decision-making. Furthermore, Desigan et al. (2006) conducted a study among women in India and found that other factors, such as cumbersome procedures and formalities, were likely to pose challenges for women engaging in stock trading.

Furthermore, Hira and Loibi (2008) conducted a related study of American households and found that female stock traders perceived stock market investment decisions to have a bearing on their experience of stress due to their difficulty and time-consuming nature. Another similar study conducted by Loibi et al. (2007) relied on descriptive statistical methods for gathering and analyzing data and found that the lack of trading information, excessive dependence upon simplified heuristics for decision-making, and heavy reliance upon choice-making strategies based on financial advisory guidelines were likely to contribute to the non-static as well as complex nature of trading choices and actions conducted by women. This could be extended to women in the Saudi context.

Mishra (2007) conducted a study on the limited participation of women in stock market trading activities. Their study focused on the context of India and relied on a sample of 1,200 Indian women. Relying upon chi-square tests and simple proportionalities, the researcher found that high risks encompassing stock market trading decisions were likely to prevent women from actual involvement in stock market trading. Moreover, some 
studies using methodologies, such as Likert scales and descriptive statistical approaches, also pointed out that the language and style employed by professionals in the financial services sector were significant bottlenecks that limited potential female traders from participating in financial matters (Bannier \& Neubert, 2015).

\subsection{The Role of Gender in Stock Market Participation}

In order to investigate the role of gender in stock market participation, Becker-Blease and Sohl (2008) conducted a longitudinal study using univariate as well as multivariate analytical methods. Females involved in angel investment were more likely to have lower confidence levels and faced greater restrictions in terms of their access to the startup capital that would be necessary for their successful involvement in the stock market in comparison to male stock market traders (Edelman et al., 2018). Other related studies relying on the use of population statistics, chi-square based automatic interaction detection procedures, exploratory cluster analyses, and cross-tabulation analyses, along with the tests for statistical significance as the primary methods have been conducted (Edelman et al., 2018). Based on these studies, there is a general disinterest in stock market participation, coupled with a lack of perception concerning its relevance along with the stressful events and glaring bottlenecks that are more likely to prevent women from building their skills in financial matters.

In a relevant study of 408 male and 342 female participants, Nath et al. (2009) made use of descriptive statistical methods, t-tests, confirmatory factor analyses, regression analyses, bivariate, and univariate analyses of variance (ANOVA) methodologies to examine the factors contributing to women's low participation in stock trading. Their findings revealed that the way in which the provision of pertinent information to guide stock market investments was being made failed to offer adequate enfranchisement to women.

In a study of a sample of 150 women, Kathirvel (2010) relied on the methods of chi-square testing and simple proportionality computations to explore the factors contributing to the limited involvement of women in stock trading. Their study found that the inadequacy of basic knowledge regarding the various typologies of stock investment was more likely to prevent female traders from making high return stock market investments. Moreover, in a multi-state study involving 500 respondents drawn from 18 countries, and based on the use of t-tests, descriptive statistical analyses, and logit regression, Jacobsen et al. (2010) found the absence of optimism to be a contributing factor to the limited stock market participation of women in terms of shareholdings.

In 2011, Donahue conducted a multi-design study involving a survey of a sample of at least a thousand adult respondents, a survey of at least five-hundred households, and the administration of questionnaire instruments to one thousand participants. The researcher also interviewed a national cross-sectional sample of 1,010 adult respondents, which was concluded by interviews involving a representative sample comprising of 1,085 grade nine students. The researcher found that women were unable to reach a particular extent of financial behavior without realizing a corresponding increase in the level of access to capital as well as improvements in their knowledge of financial matters.

Almenberg and Dreber (2015) conducted a study on a sample of 1,300 adult respondents drawn from Sweden. Their study relied upon the utility of descriptive statistics in conjunction with probit regression models to explore the factors contributing to women's limited participation in stock trading. Their findings suggested that both lack of financial literacy and risk aversion had an impact on the limited participation of women in stock market trading activities.

\subsection{Trading Success Factors}

Most of the previous studies explored the role of transactional and informational cost explanations of the rare participation of women in stock market trading (Laakso, 2010). Because stock trading involves time and financial resources, women drawn from wealthier households are more likely to participate in stock market trading, and investment in stocks is less likely to be perceived as a barrier to potential involvement in stock trading. Based on the empirical evidence from previous research, the psychosocial barriers tend to make stock market participation uncomfortable for some women, including women in Saudi Arabia (Laakso, 2010). A significant number of studies have established that men tend to trade more aggressively compared to their female counterparts, and that male traders have a greater likelihood of investing in a stock. In this regard, education has been found to bear a significant positive influence on the stock market participation of individuals, regardless of their wealth status and incomes (Laakso, 2010). Additionally, some studies have explored the role of education in financial decision-making across various cultural contexts.

Risk aversion is another factor that explains the limited participation of Saudi women in stock trading. In general terms, variations in risk aversion tend to influence the investment choices of women in a way that the more risk-averse women in the country are likely to forego the comparatively greater expected returns on investments 
for earnings with lower variance factors. Based on the standpoint of the portfolio theory of stock investment and the proportion of wealth one has, the willingness to invest in risky stockholding assets is a function of the extent or level of the individual's risk aversion in a manner that women who are risk-averse are likely to have safer holdings of portfolios. Risk aversion is arguably impactful not only on one's portfolio structure but also on their overall decision-making to participate in stock trading.

\subsection{Social and Cultural Barriers}

Various studies on the limited stock market involvement of women have cited the influence of culture on the potentiality of women to hold stocks and focused on the cultural elements of financial activities. Stock participation is driven by distance, language, as well as culture, and culture has been shown to explain the variations in individual stockholder rights in the west vis-à-vis countries in the Arab world (Arora \& Kumari, 2016).

Social interaction remains a key factor cited in the literature on behavioral finance. The stock market involvement of women can be driven by sociability in various ways as well as via divergent networks. Previous studies have explored the importance of peer groups in influencing the financial decision-making of individuals. For instance, research has pointed out that the choices concerning the participation in employer-funded retirement planning initiatives are driven by the decisions made by coworkers (Arora \& Kumari, 2016).

Prior studies also highlight precise explanations of the social interaction mechanisms in understanding the stock market participation of women and other individuals. Through various channels, social interaction has been shown to stimulate the participation of individuals in stock market operations. Firstly, information exchanges via verbal communication or observational learning could encourage more women to participate in the stock market (Laakso, 2010; Vohra \& Kaur, 2016). Secondly, women might also enjoy the discussion of investment with their fellow peers, and thus, are more likely to participate in stock market investment comparatively and productively (Vohra \& Kaur, 2016).

Sociability and social learning are also other mechanisms via which financial awareness might be achieved in case there is a scarcity of information distribution. Increased financial unawareness among Saudi women and their financial illiteracy has the potential to raise concerns as women in the country are faced with increasingly complex choices in personal and family finance as well as retirement planning (Vohra \& Kaur, 2016). Based on these findings, enhancement of financial awareness has the potential to increase the stock market participation of Saudi women, although it may not be able to fully explain the low rates of stock ownership among this segment of the Saudi population.

\subsection{Summary}

The literature review has shown that a gap exists in the body of knowledge regarding women and trading aspects in Saudi Arabia. The existing research does not fully account for the mechanism in which education influences the investment decision of women. Education has the potential to change the behaviors and decisions in multiple fashions; through increased cognitive skills as well as the financial literacy of women, or by impacting their social networking, employment opportunities, and attitudinal and belief preferences (Laakso, 2010). As such, education has been shown to reduce the cost of stock market involvement by women, including Saudi female stock traders, owing to the greater ease with which individuals are able to understand the risks and regards of stock trading for actualized participation.

Several other studies identified from previous literature hold that individuals who interact with their neighbors or who attend religious gatherings together have a greater likelihood of participating in the stock market compared to non-social people. In general, an increase in the level of community stock ownership is linked to an increase in the potential for an individual to participate in stock market trading. According to Arora and Kumari (2016), stock market participation is influenced by the involvement of local peers and is based on the positive financial outcomes of the peers.

Despite the findings from the existing literature, there continue to be concerns surrounding the likelihood of unobserved attributes to influence stock market participation decision-making as well as the metrics of social interactions. Various measures, including education, religious participation, active involvement in social organizations and clubs, and one's marital status, maybe interconnected and correlated to stock market involvement (Vohra \& Kaur, 2016). For instance, how people react to public information, rather than the verbal communications may influence their trading behavior, and, therefore, the effect of social interaction on the stock involvement of Saudi women may partially remain unclear. 


\section{Methods}

The method and research designed adopted a Descriptive Design, which is a qualitative study. The study is mainly based on qualitative research design and involves data analysis of the interview responses from a convenience sample of Saudi female stock traders or Saudi women working in stock trading companies in Saudi Arabia, with limited input from the use of qualitative methods. The use of qualitative research methodology is introduced based on the rationale that the study is an investigation of human attitudes as well as behavior, with the research involving an exploration of the phenomenal rareness of Saudi women in stock market participation via their own perceptions (Seznec, 2017). This analysis is augmented by a desk review of information from online academic databases as well as using the Google search engine to pinpoint the relevant peer-reviewed literature articles on the barriers Saudi women stock traders face and how they overcome such challenges to achieve success in stock trading.

The empirical approach targets to answer:

a) What are the factors of women's success in the stock trading market?

b) What are the effective strategies for reducing the impact of social barriers preventing Saudi women from participating in stock trading?

c) What are the effective strategies for reducing the impact of cultural barriers preventing Saudi women from participating in stock trading?

d) What are the effective strategies for promoting the increased participation of Saudi women in stock trading?

The present study makes use of a structured survey questionnaire and semi-structured interviews to measure the experiences and opinions of Saudi women involved in stock trading, and the most appropriate study methodology is mixed methods entailing the use of both approaches towards the collection of both quantitative data and qualitative data for the aims and objectives of the study.

\subsection{Data and Data Gathering Procedure}

Data gathering for the purposes of the present study was conducted from March to April 2019. Before the actual gathering of data for the present study, piloting was carried out with the goal of determining the overall validity of the questionnaire instrument. Several major alterations were made to the design of the instrument following a review of the feedback obtained from the pilot study. The distribution of the questionnaires was done via email, and a version of the questionnaire instrument posted online on the Survey Monkey website (SurveyMonkey, is an online survey development cloud-based software as a service company. It was founded in 1999 by Ryan Finley and Chris Finley. The company provides surveys, and a suite of paid back-end programs". for easier access by respondents. Out of the 187 questionnaires sent out, only 150 completed the survey. This accounts for a response rate of $76.7 \%$.

\subsection{Summary}

Semi-structured interviews for the purposes of the present study were organized and similarly performed by the researchers in Saudi Arabia. Before the commencement of the interviews, email and mobile phone invitations were sent to potential female participants to request their willing participation in the present study. Upon acceptance, further communications were made with the goal of securing the involvement of the identified respondents and confirming the venue, time, and date of the various interview sessions.

\section{Results}

\subsection{Interview Results and Analysis}

Table 1. Background of the interview respondents

\begin{tabular}{cccc}
\hline Number & Age & Work experience & Education level \\
\hline 1 & 29 years & 7 years & No education \\
2 & 29 years & 6 years & High school \\
3 & 48 years & 15 years & diploma \\
4 & 29 years & 4 Years & No education (self-taught) \\
5 & 50 years & 13 years & Retired chemistry teacher \\
\hline
\end{tabular}


Five (5) respondents were interviewed for this study. All the respondents were female professionals who were currently working as stock traders within the Saudi Arabia stock market. Four were married and one single; their ages varied from twenty-nine years of age to fifty years of age.

\subsubsection{Challenges Facing Women in Stock trading}

There was an admission by the women to facing a myriad of challenges when it came to stock trading. Top of their concerns was the issue that a good number of women in Saudi Arabia are denied access to education, and, hence, a good number remain illiterate concerning financial matters. They take a backseat in making financial decisions within their families, society, and the nation at large. The social constructs have ended up confining most women to basic jobs, such as taking care of the children at home as part of their obligations. There was a general concern as well about the lack of workshops and seminars or training that accept women applicants. Most of them are dedicated to male participation. This is demoralizing for most women who would love to be involved in the training as a way of furthering their own personal development.

\subsubsection{Factors Contributing to the Success of Women in Stock trading in Saudi Arabia}

Despite all the challenges faced by women, there are success stories of women who are leading the line and are at the front of stock trading participation in the Kingdom. They, such as the interviewees, represent the success stories of the many women who are involved. Education plays a huge role in the success of these women as it has helped them acquire the much-needed knowledge and understanding that allowed them to take part in stock trading. The government has also been cited as being a major contributor to women's success in this trade, simply because it has managed to challenge so many forms of social resistance against women's participation.

The women opined that stock trading, just like any other venture that requires financial input, is a risky venture. They admitted to being risk-takers and that their boldness in their approach has ensured that they are able to survive the different market forces that affect their returns. It was clear from their responses, however, that much formal training may be crucial, as it is this that determines their participation in stock trading.

\subsubsection{Reducing Cultural and Social Barriers}

Some of the social and cultural constructs in Saudi Arabia have a demeaning attitude or effect on the place of women in society, thus hindering their involvement, even in stock trading. However, it was discovered through the interviews that politics also play a role in all this and that the unity of politics and purpose of those in leadership to deconstruct some of the social misgivings about women would go a long way in preventing their isolation from participation in stock trading. The gender segregation laws must be revisited by those involved to avoid isolating close to half the country's population who are women. It was also their view that the community learns to embrace change and accept that indeed the times are changing and that it is no longer tenable to hold women back.

In terms of the qualitative aspect of data collection among the respondents, interviews were conducted, and opinions drawn concerning the impact of the cultural barriers on women's engagement in the stock market. The 5th interviewee, a 48-year-old cost accountant, believes that formal education amongst the female gender in the early stages - in the formative years through pre-school and primary school - can help to curb the cultural barriers preventing women from participating in stock trading. To her, knowledge is indeed power. Another respondent, interviewee 4, maintains that even though most Saudi women are risk-averse and conservative, they need to be risk-takers and go out of their way to challenge some of the backward cultural practices holding women down.

\subsubsection{Measures to Promote Female Stock Trading in Saudi Arabia}

A couple of measures to promote female stock trading in Saudi Arabia were discussed by the interviewees. To begin with, it was their view that classes are needed within learning institutions to promote financial literacy among women. Stock trading being a finance-related venture, requires those involved to be well versed in money matters and how it works. Secondly, it was the issue of mentorship, especially among the younger generation of women coming up in society. The interviewees felt that those who have managed to cut out a niche for themselves in stock trading should then be able to mentor the younger ladies who wish to take it up at some time in their lives. There is a need to create awareness concerning women and stock trading.

Among the interviewees, there were varying views concerning how to promote women's participation within the stock market and in stock trading. Interviewee 4 is of the opinion that the provision of more financial courses and business-related studies for more women will help improve their participation. She also emphasizes the need to ensure that there is proper mass communication about the same via mainstream and social media to enable even those in remote areas access to this information as it will encourage their involvement. The second 
interviewee's stance on this is that there needs to be a more receptive environment within Saudi society to change. For her, there needs to be an acceptance that women can do just as well as their male counterparts in stock trading. This will help erode the backward socio-cultural practices and beliefs that have held back the women over the centuries within Saudi society. The first interviewee admits that women's empowerment is sweeping across the Kingdom and that with such initiatives to embolden women within Saudi society, they are definitely headed in the right direction. The effects of such initiatives, according to her, can be felt and seen with more women taking up trading in the stock market.

\subsection{Questionnaires Results}

As per Table 1, the majority of the respondents in the study are female (53\%), and $65 \%$ of the respondents are married. The respondents were categorized into four educational levels of qualification, as shown in Table 1 . Those are having attained an undergraduate level of education comprised $34 \%$ of the respondents with those having attained a master's level of qualification, accounting for $40 \%$. A paltry $4 \%$ had attained the level of $\mathrm{PhD}$ with the others accounting for $22 \%$ of the total respondents. The study sought out respondents within the stock trading job market, and they were grouped into four categories. With reference to Table $1,4.7 \%$ of the total respondents were stock traders, whereas $2.7 \%$ of them accounted for financial analysts within the stock market, and $5.3 \%$ constituted financial managers. An overwhelming majority of the respondents at $87.3 \%$ came from other professions within the stock market.

Table 2. Summary table of respondents

\begin{tabular}{ccc}
\hline & Num. & Percentage (\%) \\
\hline Married & Marital status & $35 \%$ \\
Single & 53 & $65 \%$ \\
\hline & 97 & \\
\hline Female & Gender & $53 \%$ \\
Male & 79 & $47 \%$ \\
\hline PhD & 71 & \\
Masters & Education level & $40 \%$ \\
Undergraduate & 3 & $34 \%$ \\
Others & 55 & $22 \%$ \\
\hline Traders & 47 & \\
\hline Financial analyst & 33 & $5 \%$ \\
Financial managers & Job title & $5 \%$ \\
Others & 7 & $87 \%$ \\
\hline
\end{tabular}

\subsubsection{Factors Contributing to Women's Success in Stock Trading}

In respect of the influence of a variety of factors concerning the success of women trading in the stock market, the interviewed respondents all held divergent opinions. The key variables in question here were education, income, and well-being financially, gender, objective and subjective financial literacy, women having a lower risk tolerance than their male counterparts, connections through family or friends that previously owned shares, a self-assessment about stocks and the market, receiving of any formal training on stock trading years of experience, and the fact that some were actual traders in the stock market. A huge number of respondents (47\%) believed that education was a key contributor to success, but a combined $24 \%$ disagreed. Breaking it down, $30 \%$ of the respondents strongly agreed that education played a key role in the success of women in the stock market. However, $6 \%$ strongly disagreed citing factors, such as stock inheritance as one of the key factors, and, hence, dismissing education as a key contributor to their success.

When it comes to age as a factor, $9.01 \%$ strongly agreed that age was indeed a determining factor in the success 
among women, and $35.14 \%$ agreed that age contributed to the success. However, $28.83 \%$ of the respondents disagreed with it being a determinant of women's success in the stock market, and $2.7 \%$ strongly disagreed; the remaining $36.04 \%$ maintained a neutral stance on the issue of age. However, it may be worth noting that the age of the successful women in the trading stock market cut across a huge spectrum and was not necessarily specific for a specific demographic. Under income and financial well-being, a large percentage of the respondents, that is, $39.7 \%$, opined that it was a major factor contributing to women's success in the stock market, with $19.2 \%$ offering a dissenting opinion. Most respondents maintained a neutral stance.

Qualitatively, through the interviews, the first respondent, a 29-year-old cost accountant, opined that women's educational background does not affect their participation in the stock market. She, however, goes on to state that financial literacy played a key role in her decision to engage and trade in the stock market. Also, she is of the opinion that women with a stronger financial background and well-being are more comfortable participating in stock trading.

4.2.2 Measures That Can Be Used to Reduce the Impact of Social Barriers Preventing Saudi Women from Participating in Stock Trading

Considering the social barriers that were identified as curtailing the progress and freedom of women in participating in stock trading, a couple of measures were identified that might reduce the impact of the social barriers preventing women's participation. The respondents' views were then drawn as to whether they could have a positive effect in reinforcing the willingness or rather ability of women to take part in stock trading despite the social restrictions within Saudi society.

On the issue of public or mass education in aiding the participation of women, the majority of the respondents, that is, $33 \%$, had a strong conviction that it would assist in reducing the impact of social barriers to elevate the women and encourage them to take part in stock trading. However, $35 \%$ were strongly convinced that it would not change much in preventing the negative effects of social barriers, whereas $21 \%$ remained neutral on the subject. On the aspect of social awareness about the matter, perhaps through social and mainstream media, the respondents largely $(62 \%)$ agreed that it would aid in bringing more women on board and, in one way or another, suppress the social barriers. Another $28 \%$, however, collectively believed that not much would change even with social awareness within the society.

An increase in trust, especially by their male counterparts, as well as an increase in the capital among the women was also assessed as a variable that may encourage more to take up stock trading, and, within that sphere, a solid $67 \%$ were in agreement that it would work with $23 \%$ of the respondents having quite strong convictions about the same. Despite that, $25 \%$ were of a contrary opinion, and a significant $9 \%$ opted to remain neutral on the matter. To add to that, the results show another key variable that was examined or rather assessed during the study was community influence. This refers to the neighbors, peers, and even family of the women involved and sought to address the issue concerning whether the community had a role to play in ensuring that the social barriers do not impede women from participating in stock trading.

More than half of the total respondents agreed that the community does have a role to play in ensuring that the social barriers do not impede women from participating in stock trading, with $16.3 \%$ of the respondents possessing a strong conviction. However, $16.3 \%$ of the respondents strongly disagreed with this notion, and only $23.8 \%$ remained neutral. This, in one way or another, demonstrated that some of the shackles constraining the participation of women in this society were perhaps community-driven.

Data were also collected through the interviews of individuals, such as the second respondent during the qualitative data collection. Despite being a receptionist at a local facility, she is also a trader and financial analyst. Unlike interviewee one who does not think there is a place for public and mass education in breaking down social barriers, she holds the opinion that communication via mass media, for example through advertising, and even the mainstream media like radios, will debunk the myths associated with women's participation in trade. Socially, her claim is that the barriers experienced within society and the bias are religiously drawn. Embracing change and accepting a new way of doing things holds the key to breaking down the social constraints for women's participation in stock trading.

4.2.3 Measures That Can Reduce the Impact of Cultural Barriers Preventing Women from Participating in the Stock Market

Throughout the study, there was evidence of cultural barriers within the Saudi community that impeded the participation of women within their society from participating in the stock market and stock trading. Among the key variables of interest was the idea or notion that stock trading companies or companies within the stock 
market should employ more female employees to bridge the gap in terms of women's participation. The results from the questionnaires show that most of the respondents, that is, $70 \%$ of the respondents, strongly supported the notion with $26 \%$ of the total maintaining a strong conviction that increasing women's employment in this field would serve to reduce the impact of cultural barriers.

\subsubsection{Promoting Stock Market Participation Among Saudi Women}

There were factors considered as being crucial in perhaps promoting the participation of women in stock trading and encouraging them to get involved within the stock market. Among those considered was the perceived need to increase financial literacy among women. This could be done through training, additional finance workshops, or internship programs. In this case, $30 \%$ of the respondents strongly disagreed with $7 \%$ simply disagreeing. A combined sum of $47 \%$ agreed that this approach would work in curtailing the impact of cultural barriers, while another $16 \%$ were neutral on this matter. The issue of education also came up as the respondent's views were sought concerning whether more women needed to be educated through business and finance-related courses to bridge the gap concerning their involvement in the stock market. It is worth noting that a combined total of $85 \%$ of the respondents agreed that educating more women would help in encouraging women's participation in stock trading. This is against the earlier backdrop of a total of $47 \%$ of respondents who agreed that education played a critical role in the success of women within the stock market and stock trading. A combined total of $3 \%$ disagreed that education was an alleviating factor, with $12 \%$ opting to maintain neutrality on the issue.

In general, researchers are in concurrence that there are two broad categories of research methodology. The respondents' views were also sought concerning whether there is a need for more promotional content within media about stock trading involving women, and whether this would help in demystifying female participation in stock trading.

Under this, $72 \%$ agreed, with $29 \%$ of the respondents being strong believers that it would assist in making more women participate in stock trading by providing access to information about others who have been there and done it. A paltry $1 \%$ strongly differed, bringing the total number of those dissenting to $11 \% ; 17 \%$ neither agreed nor disagreed with this assertion. This followed a total number of $62 \%$ agreeing that the mass or public communication of women in stock trading through social or mass media would also help to restrain the effect of social barriers on the same. On the issue of a reduction in trading commissions and fees to encourage women's participation, a combined sum of the respondents of $67 \%$ agreed that this would promote women's participation with $30 \%$ to a greater degree; $11 \%$ of them refuted the assertion, and only $22 \%$ were neutral. On this, it is worth noting that interviewee one did not think that lowering the fees or commissions would aid in increasing women's participation in stock trading. Lastly, the respondents were quizzed on whether stakeholders in the industry should promote market simulation among Saudi women. Basically, 39\% agreed with $20 \%$ of the respondents possessing a strong assertion that this would work. Sixteen percent $(16 \%)$ were neutral, with a total of $25 \%$ disagreeing with this line of thought.

\section{Conclusion and Recommendations}

In summary, this study sought to address four critical issues and aspects of women taking part in stock trading within the Kingdom of Saudi Arabia. All this was done considering the socio-cultural and political drawbacks that, over time, have ensured that women in most Arabian countries are deprived of the equal opportunities that their male counterparts enjoy, equal access to education and training, and even equal involvement in the region's political environment. The first critical issue to be addressed concerned what factors have contributed to the success of women who have become trailblazers in their participation within stock trading and the stock markets. Several variables were involved at this stage of the study, but only a couple really stood out. To begin with, education was a key variable identified by the respondents as having contributed to the increased penetration and success of women stock traders.

Age also came up as a factor for success, especially among women of the younger generation as opposed to the older ones. However, this may not have been a critical factor considering that the ages of the successful women trading in stock covered a wide spectrum, as evidenced by the qualitative data collected. Adding to that as a factor for success was solid financial backing and well-being. A large percentage of the respondents concurred through the qualitative data collected that stock trading was a venture that requires risk-taking.

Moving onto measures that can reduce the effect of social barriers as a deterrent for women to take up stock trading, the critical aspect that came out clearly was awareness. In this case, this meant ensuring the dissemination of information through mass media, which, in this case, is through the radio, television, advertisements, and even the print media. It is worth noting that social media and social circles also have a role to play in this. This was backed up by the interviews in which the respondents agreed that a big part of the fight 
to change the tide could be done through ensuring public communication and mass education. In addition to that, the community was also highlighted as having a role to play in ensuring that women can take up jobs and positions within the stock trading and business fraternity. This may be through disposing of retrogressive social barriers and embracing women's empowerment as a positive and revolutionary idea in encouraging the participation of the female gender in stock trading.

To begin with, the respondents unanimously agreed that the training of women in business and financial literacy courses would better equip them to join the market and that, in turn, this will improve the uptake of stock trading as a viable investment opportunity for women. A considerable number of respondents, concerning the provision of market simulations in stock trading for Saudi women, agreed that it would at least help in easing the understanding and bringing to the attention of many more women what goes on in the stock trading market and that this would promote a greater influx of women. As per the qualitative interviews, the respondents agreed that it might not be enough to just train women and that boot camps or clinics where women could go to access data on stock trading needed to be provided. The issue of women's empowerment also came out strongly as one of the ways to promote women's involvement. This may be through financial incentives or knowledge and mentorship programs.

In conclusion, the study clearly shows that education and proper access to information are the key drivers of success among Saudi women who have taken up the stock trading venture. It is clear from these results of the study that the socio-cultural beliefs and practices still play a major role in holding back women from taking part in stock trading. As such, initiatives, such as empowerment among the women, coupled with the sensitization of men against the discrimination and oppression of their counterparts, will go a long way in addressing the perceived retrogressive beliefs. Information is power, and education of the masses is crucial if more and more women are to take up stock trading in Saudi Arabia. Whether through mass or social media, the word must be disseminated to all to ensure that in a world that is increasingly accepting women in frontline positions, the Kingdom is not left behind.

The research involved finding out the rareness of female Saudi traders in the stock market. However, it is worth noting that involvement in stock trading is not the only professional position within the stock market. Further research could be carried out to determine the enrolment of women into stock trading training as well. This will provide much more insight into how many women are able to enroll in the programs that provide training and continuous education within the stock trading venture and point out any disparities that may arise.

\section{References}

Abalkhail, J. M., \& Allan, B. (2016). "Wasta" and women's careers in the Arab Gulf States. Gender in Management: An International Journal, 31(3), 162-180. https://doi.org/10.1108/GM-02-2015-0006

Al-Asfour, A., Tlaiss, H. A., Khan, S. A., \& Rajasekar, J. (2017). Saudi women's work challenges and barriers to career advancement. Career Development International, $\quad 22(2), \quad 184-199$. https://doi.org/10.1108/CDI-11-2016-0200

Al-Asmari, M. (2008). Saudi labor force: Challenges and ambitions. Journal of King Abdulaziz University: Arts and Humanities, 16(2), 19-59.

AlMunajjed, M. (2009). Women's education in Saudi Arabia: The way forward. Booz \& Company, 1, 23.

Almenberg, J., \& Dreber, A. (2015). Gender, stock market participation, and financial literacy. Economics Letters, 137, 140-142. http://doi.org/10.1016/j.econlet.2015.10.009

Al-Yahyaee, K. H., Al-Hadi, A. K., \& Hussain, S. M. (2017). Market Risk Disclosures and Board Gender Diversity in the Gulf Cooperation Council (GCC) Firms. International Review of Finance, 17(4), 645-658. https://doi.org/10.1111/irfi.12123

Arora, M., \& Kumari, S. G. (2016). Effect of Cognitive Abilities, Emotional Intelligence, and Self Esteem on Investment Decision Making: A Prospect Theory Approach (Doctoral dissertation).

Bajtelsmit, V. L., \& Bernasek, A. (1996). Why do women invest differently than men? Financial Counseling and Planning, 7, 1-10. https://doi.org/10.2139/ssrn.2238

Bannier, C. E., \& Neubert, M. (2016). Gender differences in financial risk-taking: The role of financial literacy and risk tolerance. Economics Letters, 145, 130-135. https://doi.org/10.1016/j.econlet.2016.05.033

Barber, B. M., \& Odean, T. (2001). Boys will be boys: Gender, overconfidence, and common stock investment. The Quarterly Journal of Economics, 116(1), 261- 292. https://doi.org/10.1162/003355301556400 
Becker-Please, J. R., \& Sohl, J. (2008). Confidence and angel investors: Does GENDER matter? Working paper. https://ssrn.com/abstract=1345983

Brannen, J. (2017). Mixing methods: Qualitative and quantitative research. Routledge. https://doi.org/10.4324/9781315248813

Bryman, A. (2016). Social research methods. Oxford University Press.

Deo, N. (2006). Is globalization our friend? Women's allies in the developing world. Current History, 105(689), $105-111$.

Desigan, C. G., Kalaiselvi, S., \& Anusuya, L. (2006). Women Investors' Perception towards Investment-An Empirical Study. Indian Journal of Marketing, 36(4). Retrieved from http://www.indianjournalofmarketing.com/index.php/ijom/article/view/34314

Donohue, M. A. (2011). Financial literacy and women: Overcoming the barriers. Open Access Dissertations, University of Massachusetts, Amherst, Paper 395, 1-131.

Dyer, A., McDowell, L., \& Batnitzky S. (2002). A middle - class global mobility? The working lives of Indian men in a west London hotel. Global Networks, 8(1), 51-70. https://academic.oup.com/humupd/article/14/6/605/633528

Edelman, L. F., Donnelly, R., Manolova, T., \& Brush, C. G. (2018). Gender stereotypes in the angel investment process. International Journal of Gender and Entrepreneurship, 10(2), 134-157. https://doi.org/10.1108/IJGE-12-2017-0078

Embrey, L. L., \& Fox, J. J. (1997). Gender differences in the investment decision-making process. Financial Counseling and Planning, 8(2), 33-40.

Fisher, P. J., \& Yao, R. (2017). Gender differences in financial risk tolerance. Journal of Economic Psychology, 61, 191-202. https://doi.org/10.1016/j.joep.2017.03.006

Fusilier, M., \& Mueller, L. C. (2004). Client age, gender, education and perceptions of investment broker practices. Academy of Accounting and Financial Studies Journal, 8(2), 93. Retrieved from https://www.abacademies.org/articles/aafsjvol822004.pdf\#page $=99$

Global Gender Gap Report. (2020). Global Gender Gap Report 2020. [online] World Economic Forum. Retrieved from https://www.weforum.org/reports/gender-gap-2020-report-100-years-pay-equality

Gorney, C. (2016). The Changing Face of Saudi women. National Geographic February, 110-133.

Hausmann, R., Tyson, L. D., \& Zahidi, S. (2015). World Economic Forum. Global Gender Gap Report. Retrieved from http://www.weforum.org/pdf/gendergap/report2007.pdf

Hill, B., Lunn, M., Morrison, W., Mueller, J., \& Robertson, C. (2015). Saudi Arabia: An overview of executive compensation, board structure, and sustainability. Drake Management Review, 4(1/2), 20-33. https://doi.org/10.18488/journal.1.2019.92.229.239

Hira, T., \& Loibl, C. (2008). Gender Differences in Investment Behavior. In J. J. Xiao (Ed.), Handbook of Consumer Finance Research (pp. 253-270). New York: Springer.

Human Rights Watch (2016). Women and Saudi Arabia's Male Guardianship System. Retrieved from https://www.hrw.org/sites/default/files/report_pdf/saudiarabia0716web.pdf

Jacobsen, B., Lee, J. B., Marquering, W., \& Zhang, C. Y. (2014). Gender differences in optimism and asset allocation. Journal of Economic Behavior \& Organization, 107, 630-651. Retrieved from https://www.pure.ed.ac.uk/ws/files/19034597/gender_differences_in_optimism.pdf

Kannadhasan, M., Aramvalarthan, S., Mitra, S.K., \& Goyal, V. (2016). Relationship Between Biopsychosocial Factors and Financial Risk Tolerance: An Empirical Study. Vikalpa The Journal for Decision Makers, 41(2), 117-131. https://doi.org/10.1177/0256090916642685

Kathirvel, N. (2010). Women Investors'perception towards Online Trading in Tamilnadu with Special Reference to Coimbatore District. TECNICA Journal of Management Studies, 5(1), 75-88.

Kattan, M. M., de PablosHeredero, C., Botella, J. L. M., \& Margalina, V. M. (2016). Factors of Successful Women Leadership in Saudi Arabia. Asian Social Science, 12(5), 94-107. https://doi.org/10.5539/ass.v12n5p94

Kaur, M., \& Vohra, T. (2012). Women and stock market participation: A review of empirical evidence. 
Management and Labour Studies, 37(4), 283-293. https://doi.org/10.1177/0258042X13484868

Loibl, C., \& Hira, T. K. (2009). Investor information search. Journal of economic psychology, 30(1), 24-41. https://www.academia.edu/download/45195400/Investor_information_search20160429-22152-kmzhqm.pdf

Laakso, E. (2010). Stock market participation and household characteristics in Europe. Master Thesis. Aalto University School of Economics, Finland. Retrieved from http://urn.fi/URN:NBN:fi:aalto-201111181429

Loibl, C., Lee, J., Fox, J. J., \& Mentel-Gaeta, E. (2007). Women's high-consequence decision making: A non-static and complex choice process. Journal of Financial Counseling and Planning, 18(2), 35-47.

Lusardi, A., Mitchell, O. S., \& Curto, V. (2010). Financial literacy among the young. Journal of Consumer Affairs, 44(2), 358-380. https://doi.org/10.3386/w15352

Maxwell, J. A. (2016). Expanding the history and range of mixed methods research. Journal of Mixed Methods Research, 10(1), 12-27. https://doi.org/10.1177/1558689815571132

Mishra, B. (2007). Investment decision making process by employed women. New Delhi: Mahamaya Publishing House.

Nath, L., Holder-Webb, L., \& Wood, D. (2009). Will women lead the way? Gender and Information Preferences in Investment decisions. https://doi.org/10.2139/ssrn.1341897

Patten, M. L. (2016). Questionnaire research: A practical guide. New York: Routledge.

Rajkhan, S. (2014). Women in Saudi Arabia: Status, rights, and limitations. University of Washington; Bothell.

Salem, R. (2017). Evaluating the Investment Behaviour of Women in Arab Capital Markets: A Case Study of Saudi Arabia and Jordan (Doctoral dissertation). Anglia Ruskin University). Retrieved from http://arro.anglia.ac.uk/id/eprint/702488

Sekaran, U., \& Bougie, R. (2016). Research methods for business: A skill-building approach. Chichester, West Sussex, United Kingdom: John Wiley \& Sons.

Seznec, J. F. (2017). The financial markets of the Arabian Gulf. New York: Routledge.

Vohra, T., \& Kaur, M. (2016). Awareness and Stock Market Participation of Women: A Comparative Study of Stock Investors and Non-Investors. IUP Journal of Management Research, 15(4), 22-38. Retrieved from https://ssrn.com/abstract $=3065890$

Vohra, T., \& Kaur, M. (2018). Determining Reasons for Lower Participation of Women in Indian Stock Market: A Comparative Study of Stock Investors and Non-investors. Jindal Journal of Business Research, 7(2), 87-102. https://doi.org/10.1177/2278682118777032

Walliman, N. (2017). Research methods: The Basics. New York: Routledge.

\section{Copyrights}

Copyright for this article is retained by the author(s), with first publication rights granted to the journal.

This is an open-access article distributed under the terms and conditions of the Creative Commons Attribution license (http://creativecommons.org/licenses/by/4.0/). 